J. MACROMOL. SCI.-CHEM., A16(2), pp. 441-450 (1981)

\title{
On the Structure of Beta-Cyclodextrin Polymer Adducts
}

\author{
MIECZYSEAW MACIEJEWSKI and ZYGMUNT DURSKI \\ Institute of Organic Chemistry and Technology \\ Warsaw Technical University \\ Warsaw, Poland
}

\section{A BS TRAC T}

Beta-cyclodextrin/poly(vinylidene chloride) adduct (beta$\mathrm{CD} \cdot \mathrm{PVDC}$ ), after dehydrochlorination, and beta-CD/vinylidene chloride-allyl chloride copolymer result in unit cell crystals in which the beta-CD excluded volume $\left(1410,1440 \AA^{3}\right)$ falls in with the lowest values of that in low molecular adducts (1410$1770 \mathrm{~A}^{3}$ ). Based on these, the coaxial position of the polymer chain and the cycle molecules in beta-CD.PVDC and in its derivatives was determined. Hydrogen bonds are assumed to be the main ones between the PVDC chain and beta-CD molecules as well as between beta-CD molecules themselves. They link the adduct components to each other with the aid of covalent bond forces. A higher degree of space filling of the PVDC chain in beta-CD adduct canal cavities (0.80) than for the PVDC crystal lattice itself $(0.76)$ is assumed to be the basis of the topology in the adducts.

\section{INTRODUCTION}

Some papers have been published on the nonchemical character of beta-cyclodextrin compounds with poly(vinylidene chloride) (PVDC) and with vinylidene chloride-allyl chloride copolymer $[\mathrm{P}(\mathrm{VDC}+\mathrm{AC})]$ 
[1-4]. An inclusion structure with canal elements constructed of the beta-CD molecules and a topological one is taken in cnnsideration for these compounds. New data actually obtained from X-ray investigations allow the polymer adduct structure to be more clearly known. It was especially possible to determine the position of the polymer chain in relation to the beta-CD canal in the adducts. The lack of suitable single crystals makes a full structural investigation impossible. However, it is very useful to compare the actually available $\mathrm{X}$-ray data of the polymeric adducts with those of low molecular ones. When they are compared, it is possible to make the hypothesis that only the intraannular (coaxial) position of the polymer chain in ralation to the ring beta-CD molecules in the adducts can be acceptable. We assume the coaxial arrangement of low molecular cyclodextrin adducts to be already proved. Unequivocal results were obtained by a full $X$-ray investigation of the structure of the sodium acetatealpha-CD adduct [5] and the ' ${ }^{2} \mathrm{H}$ NMR study of some beta-CD inclusion compounds [6].

Based on the data we have obtained, it is possible to discuss the value of the interaction forces between the PVDC chain and beta-CD molecules in the adduct as well as the degree of space filling of the polymer in the canals. The forces were evaluated to be of covalent order. This explains the greater stability of the beta-CD.PVDC and beta-CD $\cdot \mathrm{P}(\mathrm{VDC}+\mathrm{AC})$ adducts over low molecular ones. Great inclusion forces, however, do not exclude the occurrence of topological bonds. These can be derived from a tight congruence with the inside of the beta-CD canals.

\section{DISC USSION}

The stability of polymer adducts alone, higher when compared with that of low molecular ones [1-4], supports the coaxial position of the polymer chain in the adducts investigated. If one supposes that the beta-CD molecules exist as pendant additive groups along the PVDC chain, the stability of beta-CD.PVDC and beta-CD.P(VDC $+\mathrm{AC})$ should not differ from the stability of low molecular compounds/ cyclodextrin adducts. The length of a molecule being included in the adduct should not play any role in that case. As examples of polymer adducts in which the included molecules exist as side additive groups of a polymer chain, the products of polymerization of urea and thiourea adducts with some monomers $[7,8]$ can be mentioned. These polymer adducts readily dissociate when undergoing water action, resulting in free molecules of the polymer. On the contrary, betaCD.PVDC does not dissociate either in water (readily dissolving beta$\mathrm{CD}$ and giving rise to dissociation of low molecular adducts) or in cyclohexanone (dissolving PVDC). Traces of PVDC are extracted from the adduct only with the aid of a boiling water/cyclohexanone mixture $|4|$. 
Not all the adduct of interest could be investigated directly by $\mathrm{X}$-rays. Beta-CD.PVDC, for instance, the main object of this research, is an amorphous substance. Beta-CD.P(VDC $+\mathrm{AC})[2]$ and some fractions of beta-CD.PVDC after dehydrochlorination (beta-CD.DHPVDC) have been obtained as crystal. X-ray investigations focused on cell dimension determination which were used as the basis of estimating the adduct structure. Based on the volume and the space group of the crystal, the position of a polymer chain in relation to beta-CD molecules in the adducts can be assumed. It seems that if the part of the cell volume taken by the beta-CD molecule together with the included one (beta-CD excluded volume) is not greater than that of a low molecular system, the polymer chain cannot take place outside of the canal of the relatively rigid cyclodextrin molecules, and the only space available for it is the free intracanal (intraannular) position like in the case of small molecules inclusion. An extraannular position (a long chain substituent of the beta-CD molecule) would lead to a significant increase of the bcta-CD excluded volume.

Beta-CD excluded volume in cells was calculated as follows. It is known that in some cases the space group indicates directly the amount of identical molecules in a cell [9]. The amount can also be estimated on the basis of the specific volume of the beta-CD molecule. This can be found in turn from the data of the beta-CD/water adduct cell (Table 1), which is known to have two beta-CD molecules and 14 molecules of water [10]. Dividing the cell volume by 2 after the 14 water molecules volume are excluded, a value of $1357 \AA^{3}$ is obtained. This value will not change significantly in other beta-CD adducts. By knowing the cell volumes, the amount of beta-CD molecules (approximately) as well as beta-CD excluded volume in the adduct can be calculated (Table 1). In order to know the precise amount of beta-CD molecules in an adduct, we assume that, according to the symmetry demands of crystals, a cell contains only one molecule of beta-CD or its multiple $n$ in the range of the space group P1, two molecules of that or $\mathrm{n} 2$ molecules in the range of the space group $\mathrm{P} 2_{1}$, and either $\mathrm{n} 2$ or $\mathrm{n} 4$ molecules of beta-CD in the range of the space group C2.

The cell parameters of some low molecular crystals have been taken from literature [10-12] and some of them were determined by us (Table 1).

It was impossible to obtain a single crystal form of beta-CD.P(VDC $+\mathrm{AC}$ ) and directly determine the cell dimensions. However, they could be estimated by comparison of the powder X-ray patterns of beta$\mathrm{CD} \cdot \mathrm{P}(\mathrm{VDC}+\mathrm{AC})$ and of the monomer adduct of beta- $\mathrm{CD} /$ methyl methacrylate [2]. The last one could also be isolated as a single crystal substance, and cell dimensions have been determined for it [13]. Because of the identity of the X-ray patterns obtained for both substances, the cell dimensions were assumed to be common for them. The cell dimensions were obtained directly in the case of the fraction called "monocrystallic" (MF) [13], which is one of the fractions of beta-CDDHPVDC [4]. It crystallizes as a complex of free beta-CD 


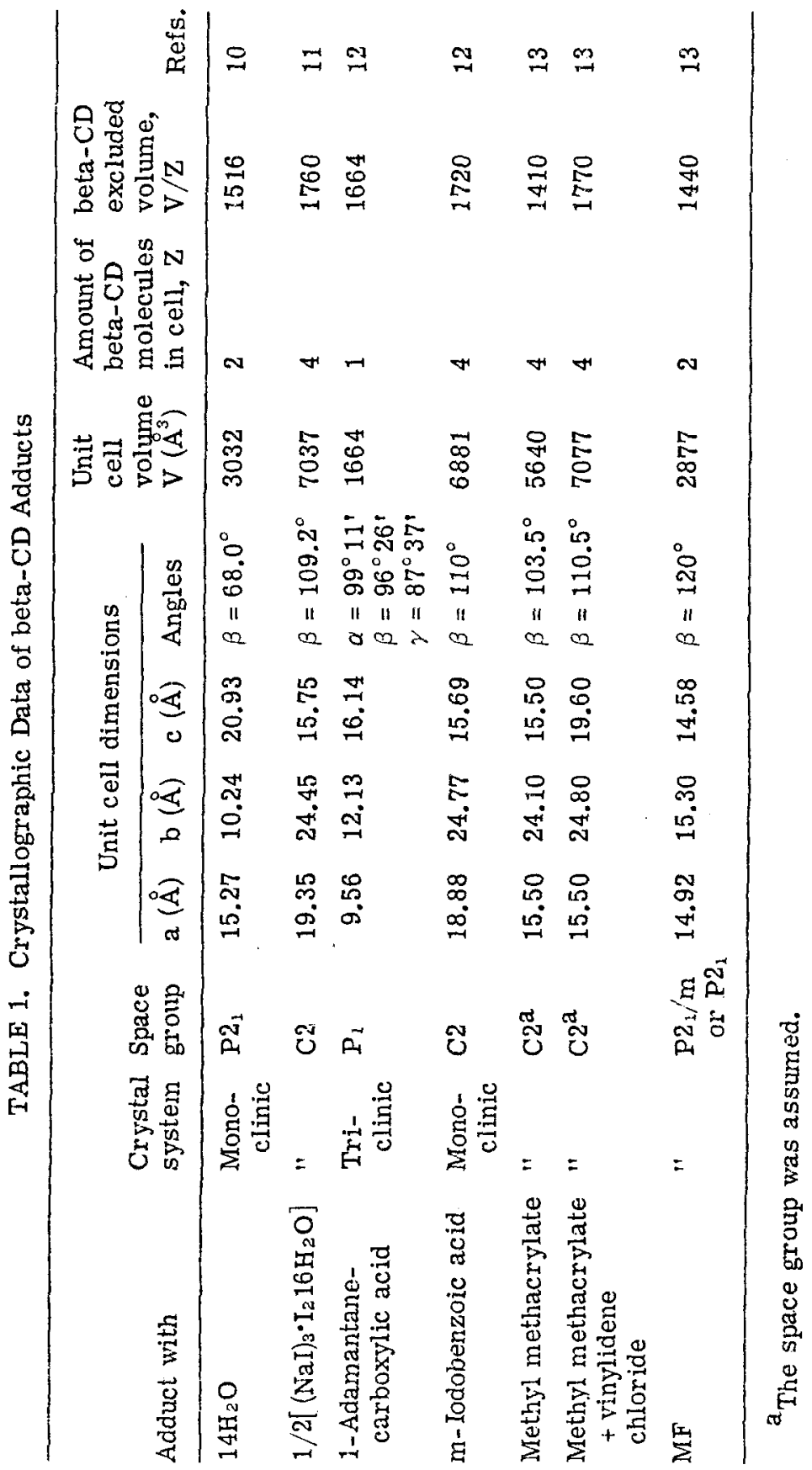


(83 wt\%) and beta-CD (12 wt\%) bound to the polymer (5 wt\%) [4]. The cell of MF differs from other known beta-CD adducts for which the cell dimensions are usually multiples of 10,12 and $16 \AA[12]$. MF crystallizes in a pseudohexagonal structure, i.e., of approximately the same " $a$ " and " $b$ " values (Table 1). Although most beta-CD exists as free molecules, MF crystallizes in a different way than low molecular adducts. An influence of the presence of the polymer chain in the adduct on the molecular arrangement in the beta-CD crystal lattice is evident.

However, the most important thing in our considerations is that the excluded volume taken by the beta-CD molecule in the polymer adduct cell is not greater than that taken by beta-CD molecule in low molecular ones. What is more, the beta-CD excluded volume in the polymer adducts falls in with lowest values of low molecular ones (1410 and $1440 \mathrm{~A}^{3}$ ) (Table 1). This can only be explained by the intraannular (coaxial) position of the polymer chains: $\mathrm{P}(\mathrm{VDC}+\mathrm{AC})$ and DHPVDC. There is also a coaxial structure in beta-CD.PVDC, from which beta-CD.DHPVDC is derived.

We have also isolated another crystalline structure which contains the polymer adduct components and free beta-CD molecules. It is identical with the beta-CD/water adduct (identical $X$-ray diffraction patterns, Fig. 1). It is formed in the same solution from which the MF crystallizes when an excess of beta-CD is added. The corresponding elution

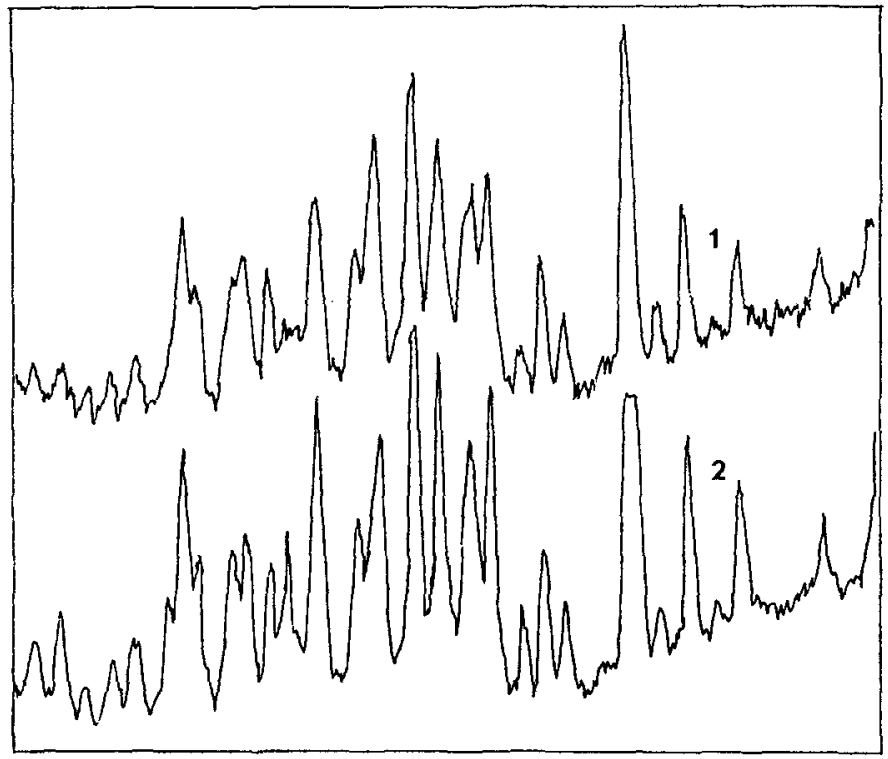

FIG. 1. X-ray diffraction patterns of (1) crystal complex of betaCD.DHPVDC and free beta-CD molecules; (2) beta-CD/water adduct [13]. 


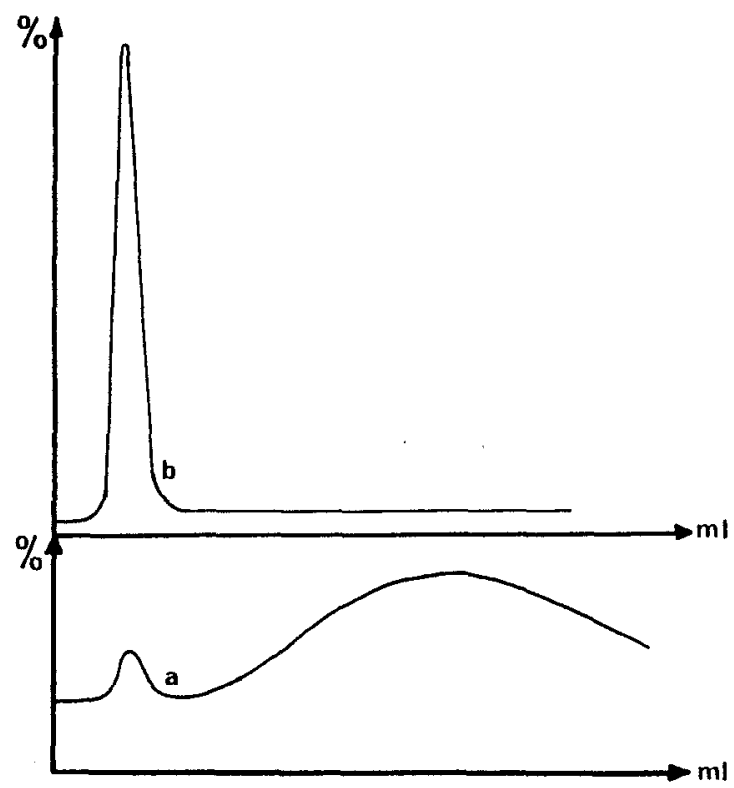

FIG. 2. Elution graphs (Curve a determined according to RI, Curve $b$ according to UV) of crystal complex of beta-CD.DHPVDC and free beta-CD molecules.

graphs (Fig. 2) show a $6.5 \%$ polymer adduct content. Perhaps such a low content of the polymer adduct does not change the crystalline lattice of beta-CD as it does in MF. Instead, there is evidence that the polymer adduct "molecules" fit very well into the beta-CD lattice. This obviously excludes the polymer chains as pendant groups of beta-CD molecules.

It is rather certain that the intraannular position of polymer chains gives rise to high stability of beta-CD.PVDC in comparison with low molecular adducts. The forces which link the polymer chain with beta-CD molecules in that adduct can be calculated approximately. According to molecular weight determination and chemical content of the adduct $[1,2,4]$, the number-average degree of polymerization of polymer chain equals 73 in the lower fraction of the product. Three types of forces between cyclodextrin molecules and molecules included in the adducts are considered: hydrogen bonds [14], van der Waals forces [15], and hydrophobic interaction [16]. The hydrogen bonds are strongest and first occur between hydroxyl groups of dextrin. It is possible, however, that hydrogen bonds are created between cyclodextrin molecules and the compound. In the case of beta-CD.PVDC, weak hydrogen bonds (1-2 kcal) possibly 


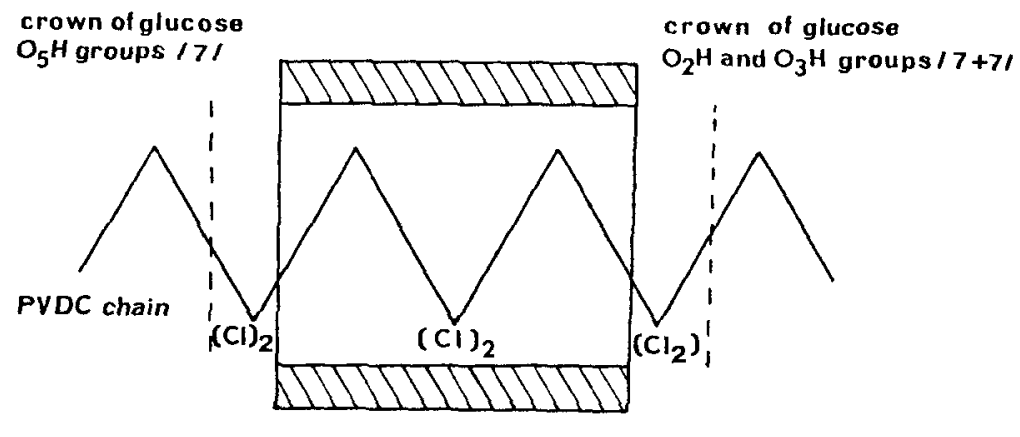

carcass of beta- CD molecule

FIG. 3. Scheme of PVDC segment ordered in beta-CD molecule canal.

occur between hydroxyl groups of beta-CD and chlorine atoms present in the polymer chain [17]. There are three $-\mathrm{CH}_{2}-\mathrm{CCl}_{2}-$ mers of the polymer chain per one cyclodextrin molecule in the adduct [1]. They form a segment of about $7.60 \AA$ length. The value equals approximately the length of the canal of one beta-CD molecule (about $8.5 \AA$ ) in low molecular adducts [11]. This means that the polymer chain in beta-CD.PVDC is entirely covered within the long canal of cyclic molecules arranged closely to each other. Of six chlorine atoms of each segment, four can probably take part in hydrogen bond creation with hydroxyl groups, being on the ends of every canal beta-CD molecule (scheme in Fig. 3). Then about 100 chlorine atoms $(2 / 3$ of the 146 in the PVDC chain) will give hydrogen bonds. This means that the force which holds the polymer chain in the beta-CD canal contains as many as several covalent bonds (above $100 \mathrm{kcal} / \mathrm{mol}$ ). The polymer chains in fractions of higher molecular weight (1000 DP) [4] will be held by stronger links.

On the other hand, account must be taken of a dissociation process which allows cyclic molecules to be removed, one after another, from the polymer chain. Such a process seems to be possible, at least at the ends of the adduct canals.

The CD molecules in beta-CD.PVDC are held to each other with the aid of seven hydrogen bonds between seven glucopyranose $\mathrm{O}_{6} \mathrm{H}$ groups on one side of the macrocycle and seven $\mathrm{O}_{3} \mathrm{H}$ groups on the other side, analogously to the alpha- $\mathrm{CD} /$ potassium acetate adduct [5]. Hydrogen bonds energy depends, of course, on the distance to which hydroxyl groups can approach each other. The real distance will be determined as soon as the single crystal form of betaCD.PVDC is obtained. Nevertheless, we know that the length of the canal in one beta-CD molecule in the adduct equals $7.60 \mathrm{~A}$, which is 
less than that in the low molecular adducts (about $8.5 \AA$ ). We also know that the excluded rolume of a beta-CD molecule in polymer adducts is less than most of those in low molecular ones. It is possible that the closer arrangement in polymer adducts is due to a decrease of the distance between cyclic molecules along the canal. It can be assumed that the length of hydrogen bonds in beta-CD-PVDC is no greater than in low molecular adducts (if not smallex) when compared to the beta-CD/water adduct where the lack of steric hindrances makes the hydrogen bonds as strong as possible. If this is the case, we have a right to assume that the hydrogen bonds which occur between cyclic molecules in beta-CD.PVDC are of at least middle value and equal to about $5 \mathrm{kcal} /$ bond [17]. This means that all hydroxyl groups (seven pairs of them between the cycles) result in a bond, which keeps neighboring $\mathrm{CD}$ molecules together with a force of about $35 \mathrm{kcal} / \mathrm{mol}$, equal to a weak covalent bond. Each hydrogen bond can be broken in sequence in low molecular adducts, and this probably gives rise to low stability. Let's consider what happens in the case of beta-CD.PVDC. When one looks at the molecular space filling model of beta-CD.PVDC, it is observed that the stiff polymer chain of PVDC is nearly congruent with the inside of the beta-CD molecules, which almost entirely limits the backward and forward rotation of the glucose units of the macrocycle around the 1,4-glucoside linkages. This means that the beta-CD molecule cannot separate from its neighbor without simultaneous cleavage of all hydrogen bonds between them. It is not easy to show this congruence graphically. A comparison of the free volume of the inside of the beta-CD molecule with the volume of the polymer segment filling it is more convenient. If the length of the canal of the beta-CD molecule is $7.60 \AA$ and its diameter, cal-o culated on the basis of data for alpha-CD and gamma-CD (5 and $7.5 \AA$, respectively) [11], equals $6.25 \AA$, we obtain an inside volume of 233 $\AA^{3}$. The volume of the polymer segment $-\left(\mathrm{CH}_{2}-\mathrm{CCl}_{2} \mathrm{j}_{3}-\right.$ has been calculated to be as much as $188 \AA^{3}$, assuming $16.27 \AA^{3}$ for $-\mathrm{CH}_{2}-$ groups and $46.46 \AA^{3}$ for $-\mathrm{CCl}_{2}$ - ones [18]. Direct comparison of the volume values obtained does not support the postulate for congruence. However, such a comparison does not reflect the real space filling in the beta-CD canal structure. Polymer molecules and aiso Jow molecular ones, even in their own crystal lattice, never reach $100 \%$ of "space filling." The degree of space filling is described by the equation $\mathrm{k}=\mathrm{zV_{0 }} / \mathrm{V}$, where $\mathrm{z}$ is the number of molecules. $\mathrm{V}_{0}$ is the volume of the molecule, and $V$ is the volume filled [18]. $k$ of PVDC for its own crystal lattice equals $0.76[18]$. We cannot expect the $k$ of PVDC to be higher in an alien lattice, particularly in the beta-CD canal whose dimensions are established covaiently and cannot be changed significantly by the configuration of guest molecules. From the volume relation $188: 233$, it follows that the degree of space filling of the PVDC chain in the beta-CD molecule canal equals 0.80 , which is thus greater than in the case of the pure PVDC crystal lattice. This means that the congruence of the PVDC chain with the inside of the canal is really good, and assuming the necessity of all hydrogen 
bonds cleaving simultaneously in the beta- $C D$ molecule during the dissociation process, is reliable if it occurs. This can be roughly depicted by a construction which is a combination of a long roller (polymer chain) on which several collars (beta-CD molecules) are situated coaxially. If the diameter of the roller is negligibiy smaller than those of the collars, the collars can move toward or away from each other, contacting or disconnecting simultaneously at all points of their plane surfaces. Such a consideration is supported by the fact that in the cases of polystyrene, poly(methyl methacrylate) poly(methyl acrylate), and polymethacrylonitrile adducts, there is much more free space in the canal (according to molecular models) to make the beta-CD glucose units mobile. These adducts are unstable and dissociate as easily as low molecular ones $[2,3]$.

Can some polymer adducts be considered as topological compounds? It seems that in the case of beta-CD.PVDC and beta$C D \cdot P(V D C+A C)$, there exist the same inclusion forces as in the low molecular adducts, therefore they differ from each other neither chemically (the lack of chemical bonds) nor physically (the same character of intermolecular bonds). A difference occurs only in the efficiency of the forces acting, and this comes directly from the geometry of the molecular arrangements in beta-CD.PVDC and beta-CD.P(VDC $+A C)$, which is expressed by the congruence of the rigid PVDC chain segments with the insides of the beta-CD molecules. The geometry of the adducts replaces topological substituents, and the lack of the latter in the polymer chain [4] should be considered as a formality only.

\section{REFERENCES}

[1] M. Maciejewski and G. Smets, Sec. Conf. Modification of Vinyl Polymers, Wroclaw, Poland, 1973; Sci. Pap. Inst. Org. Technol. Plas. Wrocław Tech. Univ., 16, 57 (1974); Chem. Abstr., 83, $43826 \mathrm{e}(1975)$.

[2] M. Maciejewski, J. Macromol. Sci.-Chem., A13, 77 (1979).

[3] M. Maciejewski, A. Gwizdowski, P. Peczak, and A. Pietrzak, Ibid., 13, 87 (1979).

[4] M. Maciejewski, Mid, In Press.

[5] A. Hybl, R. E. Rundle, and D. E. Williams, J. Am. Chem. Soc, $87,2779(1965)$.

[6] P. V. Demarco and A. L. Thakkar, J. Chem. Soc., Chem. Commun., p. $2(1970)$.

[7] J. $\vec{F}$. Brown and D. M. White, J. Am. Chem. Soc., 82, 5671 (1960).

[8] D. M. White, Ibid., 82, 5678 (1960).

[9] A. I. Kitaigorodskij, Organicheskaya Kristallokhimija, Izd. AN SSSR, Moscow, 1955.

[10] D. French and R. E. Rundle, J. Am. Chem. Soc., 64, 1651 (1942). 
[11] F. Cramer, U. Bergmann, Ph. C. Manor, M. Noltemeyer, W. Saenger, Justus Liebigs Ann. Chem., pp. 1169-1179 (1976).

[12] J. A. Hamilton, L. K. Steinrauf, and R. L. van Etten, Acta Cryst., B24, 1560 (1968).

[13] Z. Durski, M. Maciejewski, H. Boniuk, and H. Nowac zek, Data Prepared To Be Published.

[14] F. Cramer and W. Kampe, J. Am. Chem. Soc., 87, 1115 (1965).

[15] D. French, Adv. Carbohydr. Chem., 12, 250 (1957); F. Cramer, Angew. Chem., 73, 49 (1961).

[16] G. Nemethy and H. A. Schegara, J. Chem. Phys., 36, 3401 (1962).

[17] L. R. Zumwalt and R. M. Badger, J. Am. Chem. Soc., 62, 305 (1940); G. C. Pimentel, in The Hydrogen Bonds (L. Pauling, ed.), Freeman, San Francisco, 1960.

[18] B. Wunderlich, Fizika Makxomolekul, Izd. Mir., Moscow, 1976.

Accepted by editor February 6, 1980

Received for publication March 5, 1980 